\title{
Nine new species of scuttle flies, including one new genus (Diptera: Phoridae) from Iran
}

\author{
Roya Namaki-Khameneh ${ }^{1} \cdot$ Samad Khaghaninia ${ }^{1} \cdot$ R. Henry L. Disney ${ }^{2} \cdot$ Naseh Maleki-Ravasan $^{3}$
}

Received: 7 February 2021 / Accepted: 8 April 2021 / Published online: 31 May 2021

(C) The Author(s) 2021

\begin{abstract}
Namaki-Khameneh and Disney describe nine new species and one new genus Iranphora sharafkhaneensis gen. n., sp. n., Megaselia caveonectergata sp. n., M. distincta sp. n., M. fereagarici sp. n., M. flavucrurus sp. n., M. paluventer sp. n., M. polysetosis sp. n., Phalacrotophora flavidus sp. n., and Phora iranensis sp. n. from Iran. As a result, this study increased the total number of reported phorids genera and species from Iran to 12 and 78, respectively.
\end{abstract}

Keywords Phoridae $\cdot$ New genus $\cdot$ New species $\cdot$ Iran $\cdot$ Middle East $\cdot$ Palaearctic

\section{Introduction}

The Phoridae family also known as scuttle flies with about 4000 described species is considered one of the largest families of Diptera. This family is generally distributed worldwide and can be easily recognized by their reduced wing venation and humpbacked outwards characteristics. The larvae have broad natural histories ranging from true parasites, through parasitoids, specialized predators, herbivorous, fungivorous, to polyphagous saprophages. However, the biology of most species is far from fully understood and needs more investigations (Disney 1983, 1994). Megaselia scalaris Loew, 1866 and Megaselia halterata (Wood, 1910) have been reported as pests of button mushroom (Agaricus bisporus Lange), and M. scalaris has been reported as parasitoid from Iranian honey bee (Apis mellifera meda Skorikow, 1829) colonies (Talebi et al. 2003; Zamani et al. 2005; Abdi-Goodarzi et al. 2013). Previous studies from Iran have reported 11 genera and 69 species of this family (Talebi et al. 2003; Zamani et al. 2005; Disney et al. 2012; Sadeghi et al. 2013; Rabieh et al. 2013;

R. Henry L. Disney

rhld2@cam.ac.uk

1 Department of Plant Protection, Faculty of Agriculture, University of Tabriz, Tabriz, Iran

2 Department of Zoology, University of Cambridge, Downing Street, Cambridge CB2 3EJ, UK

3 Department of parasitology, Pasteur Institute of Iran, Tehran, Iran
Ebrahimi et al. 2014; Ghavami and Djalilvand 2015; Solgi et al. 2017; Namaki-Khameneh et al. 2018, 2019a, b, c, d). We make further additions below. Most species collected belonged to the genus Megaselia Rondani, 1856. Among them nine new species, including one new genus are described below.

\section{Material and methods}

In 2016 and 2018, scuttle flies were collected by Malaise traps and standard entomological hand net from grassland, wetland habitats and gardens of East and West Azerbaijan provinces. The climate in the sampling areas is temperate with cold winters and hot summers. Herbaceous and woody vegetation of the area includes Fabaceae, Asteraceae, Zygophyllaceae, Convolvulaceae and Salicaceae. All specimens were kept in $75 \%$ ethanol. After provisional identifications specimens were mounted on slides in Berlese Fluid (Disney 2001). The slides are labeled with the collection number and RHLD's notebook number and page (e.g. 50, UCMZ - 13-99). The descriptions of the new species were undertaken by Namaki-Khameneh and Disney. The photographs of whole flies were taken by using a Nikon SMZ $800 \mathrm{~N}$ stereomicroscope equipped with a Nikon D5200 digital camera. The figures of details of the slide mounted specimens were taken with the Image ProInsight system for the compound microscope. The type material of the new species is deposited in the University of Cambridge Museum of Zoology (UCMZ). Duplicate 
Figs. 1-7 Iranphora sharafkhaneensis sp. n., male. 1 Whole fly; $\mathbf{2}$ frons; $\mathbf{3}$ antenna and palp; 4 notopleuron; $\mathbf{5}$ scutellum; $\mathbf{6}$ abdomen; 7 left face of hypopygium

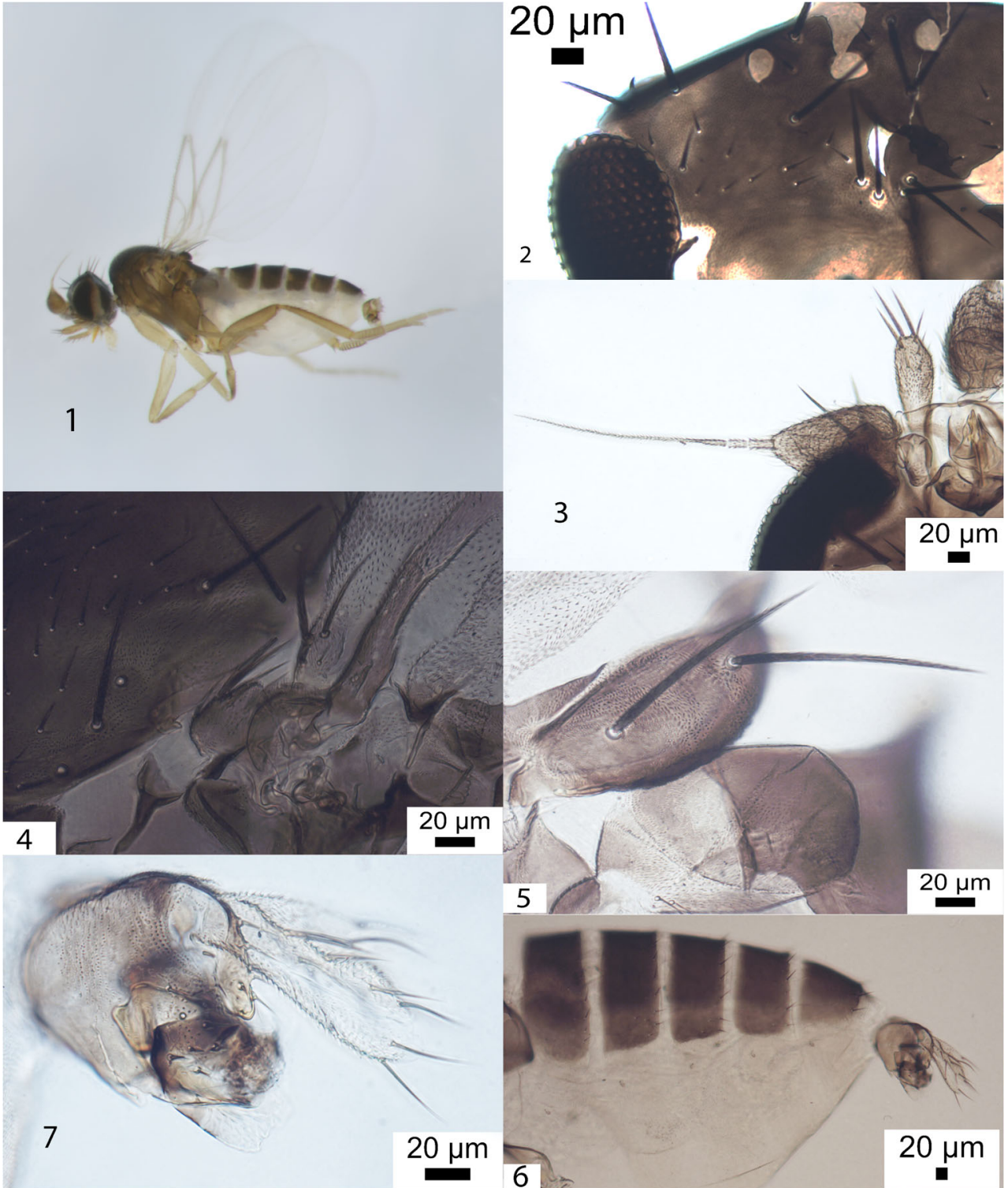

paratypes are deposited in the Insect Collection of Professor Hasan Maleki Milani, Tabriz, Iran (ICHMM).

\section{Iranphora Namaki-Khameneh \& Disney gen. $\mathbf{n}$.}

Diagnosis (male) Antennae with postpedicels longer than basal breadth, tapered and with an apical arista, the breadth of frons greater than its length, mesopleuron bare, 3 bristles on the notopleuron, only 2 bristles on the scutellum, the anal tube of the hypopygium clearly longer than the length of the epandrium, the anteroventral hairs of hind femur about as long as those of the basal half, all tibia lacking dorsal hair palisades and dorsal or anterodorsal bristles in their basal two thirds, the unforked vein 3 and long costal index of the wings, In the key to world genera (Disney 1994) it runs to couplet 38 lead 1 Adelopteromyia Schmitz, 1923, but its tapered postpedicels much longer longer and its palps much broader (Fig. $8.16 \mathrm{~b}$ in Disney 1994) immediately distinguishes it from the new genus. The detailed study by Ament (2017) indicates some similarities with Rhychomicruoteron Annandale, but its costal index is clearly less than 0.5 , vein 3 is forked, its mid and hind tibia have anterodorsal bristles in their basal halves.

Description (male) Frons more than twice as broad as long and lacking a median furrow. With 4 supra-antennal bristles, pre-ocellars and smaller mediolateral bristles and 6 bristles on vertex. Antennae with postpedicels longer than basal breadth, tapered and with an apical arista. Palps with terminal bristles longer than breadth of palp. Notopleuron with 3 bristles. Mesopleuron bare. Scutellum with only 2 bristles. Abdominal tergites with small hairs largely restricted to hind margins. Venter pale and lacking hairs. Hypopygium pale 
Figs. 8-15 Iranphora sharafkhaneensis sp. n., male. 8 Right face of hypopygium; 9 front leg; 10 middle leg; 11 hind femur and tibia; 12 tip of hind tibia and basitarsus; 13 hind tarsus; 14 wings; 15 basal half of wing

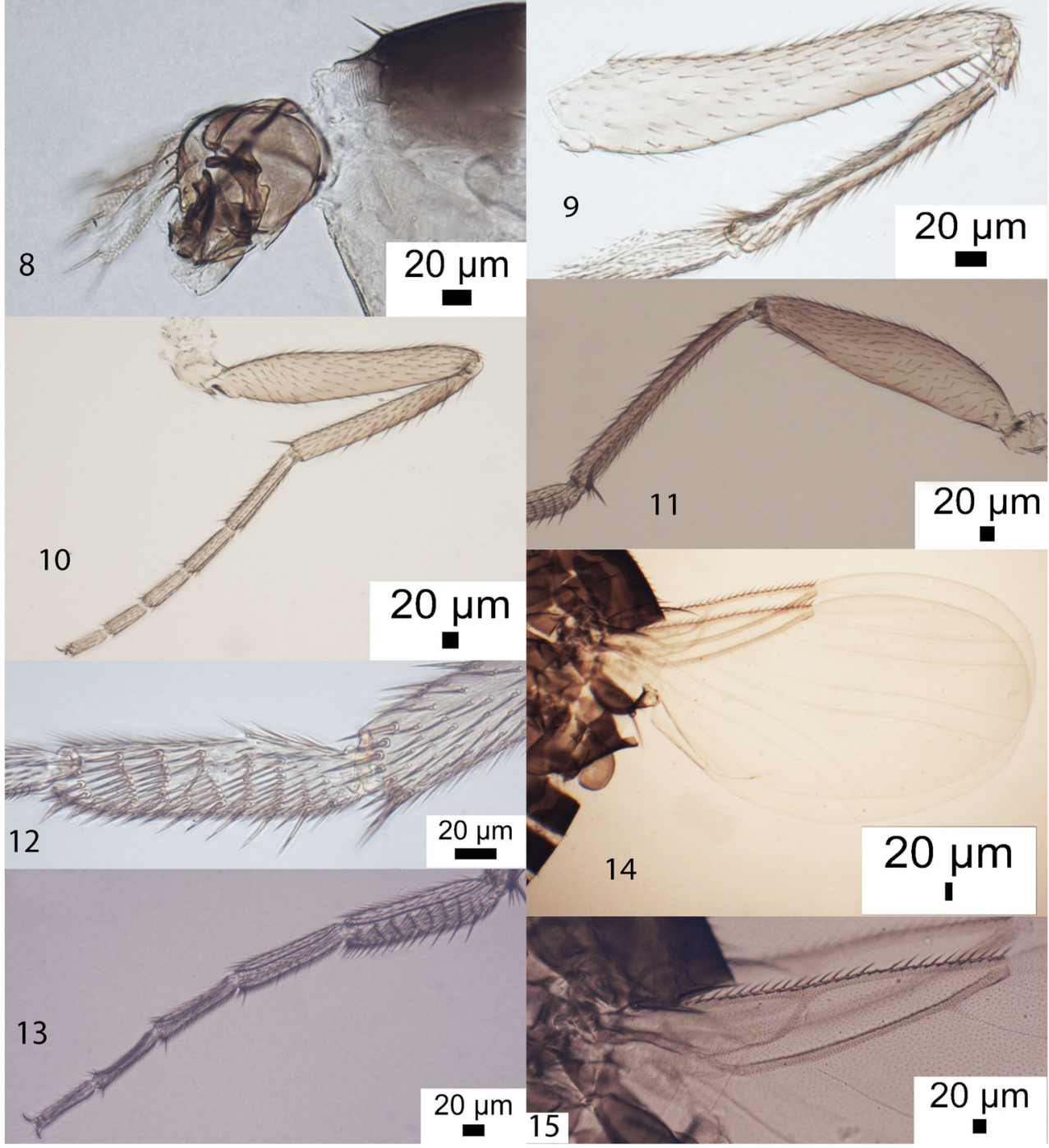

with the pale anal tube that is longer than epandrium. All tibiae lack dorsal hair palisades and the mid tibiae lack dorsal/ anterodorsal bristles in basal third. Wings with an unforked vein 3 , costal index more than 0.5 and section 1 almost as long as 2 . No axillary bristles, no hair at base of vein 3 and costal cilia short (less than $0.06 \mathrm{~mm}$ ).

Etymology Named after the country Iran.

\section{Iranphora sharafkhaneensis Namaki-Khameneh \& Disney sp. n. (Figs. 1-15)}

Description (male) Whole fly as in Fig. 1. Frons as in Fig. 2. Antenna and palps as in Fig. 3. Notopleuron as in Fig. 4. Scutellum as in Fig. 5. Abdomen as in Fig. 6. Hypopygium as in Figs. 7 and 8. Front leg as in Fig. 9. Middle leg as in Fig. 10 and hind femur and tibia as in Fig. 11. Posterior face of tip of hind tibia and basitarsus as in Fig. 12. Hind tarsus as in Fig. 13. Wings (Figs. 14 and 15) $0.87 \mathrm{~mm}$ long. Costal index
0.64. Costal ratios 0.91: 1. Costal cilia (Fig. 15) 0.02-0.03 mm long. Haltere knob brown.

Type material Holotype male, IRAN, East Azerbaijan, Sharafkhaneh City, $38^{\circ} 11.05^{\prime}$ N, $45^{\circ} 29.52^{\prime}$ E, $1313 \mathrm{~m}$ a.s.1., 21.VII.2018, Roya Namaki-Khameneh (69, UCMZ, 13-102).

Etymology Named after the locality of the holotype.

\section{Megaselia caveonectergata Namaki-Khameneh \& Disney sp. n. (Figs. 16-26)}

Diagnosis (male) In the key to the males of the British species (Disney 1989) this species runs to couplet 292. However, this couplet and those following have been replaced by a revision of the M. angusta (Wood, 1909) complex (Disney 1999) where it runs to couplet 23 lead 1 to $M$. nectergata Disney, 1999. Its hypopygium closely resembles the new species (cf. Figs. 34 and 87 in Disney 1999), but with fewer hairs on the 
Figs. 16-23 Megaselia caveonectergata sp. n., male. 16 Whole fly; 17 frons; 18 antennae, palps and proboscis; 19 side of thorax; $\mathbf{2 0}$ abdomen; $\mathbf{2 1}$ left face of hypopygium; 22 right face of hypopygium; $\mathbf{2 3}$ right face of hypandrium and penis complex

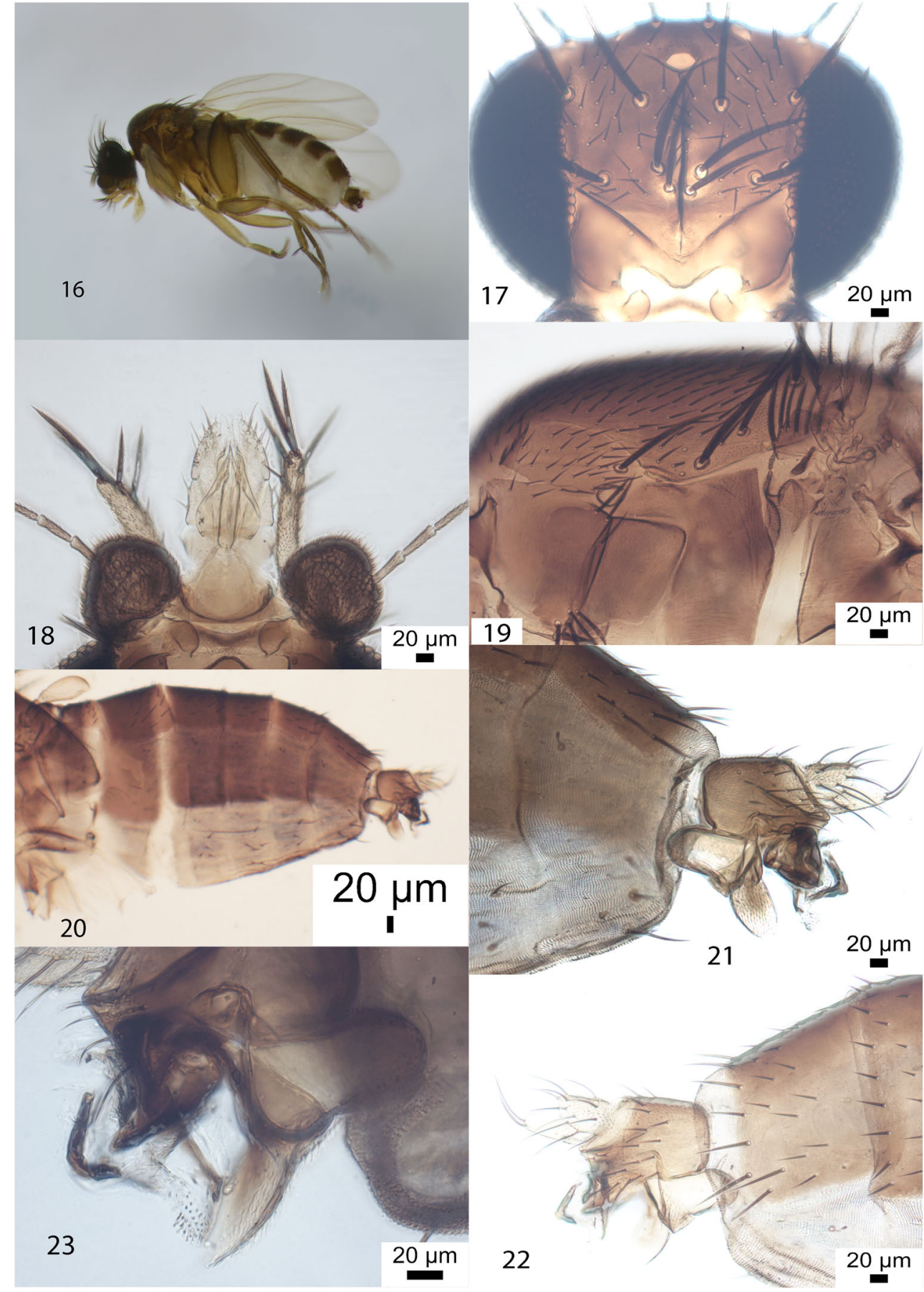

epandrium and the microtrichia of the left hypandrial lobe are flat against its lower surface unlike in $M$. nectergata. The hairs below the base of the hind femur of the latter are shorter than those of the anteroventral half.

Description (male) Whole fly as in Fig. 16. Frons as in Fig. 17, with dense but very fine microtrichia. Cheek with 4 bristles and jowl with 2 that are longer and more robust. Postpedicels, with SPS vesicles, palps and proboscis as in Fig. 18. Thorax with 2 notopleural bristles no cleft in front of these, and mesopleuron bare (Fig. 19). Scutellum with an anterior pair of small hairs and a posterior pair of bristles. Abdomen as in Fig. 20, the venter having hairs on segments 3-6 (Fig. 20). Hypopygium as in Figs. 21, 22, and 23. All legs yellow. Fore tarsus (Fig. 24) with posterodorsal hair palisade on segments $1-4$. Dorsal hair palisade of mid tibia extends about 0.55 times its length. Hairs below basal half of hind femur longer than those of anteroventral row of outer half (Fig. 25). Hind tibia with 18-20 moderately differentiated posterodorsal hairs, without anterodorsals, and spinules of 
Figs. 24-26 Megaselia caveonectergata sp. n., male. $\mathbf{2 4}$ Front leg; 25 hind femur and tibia; 26 wing

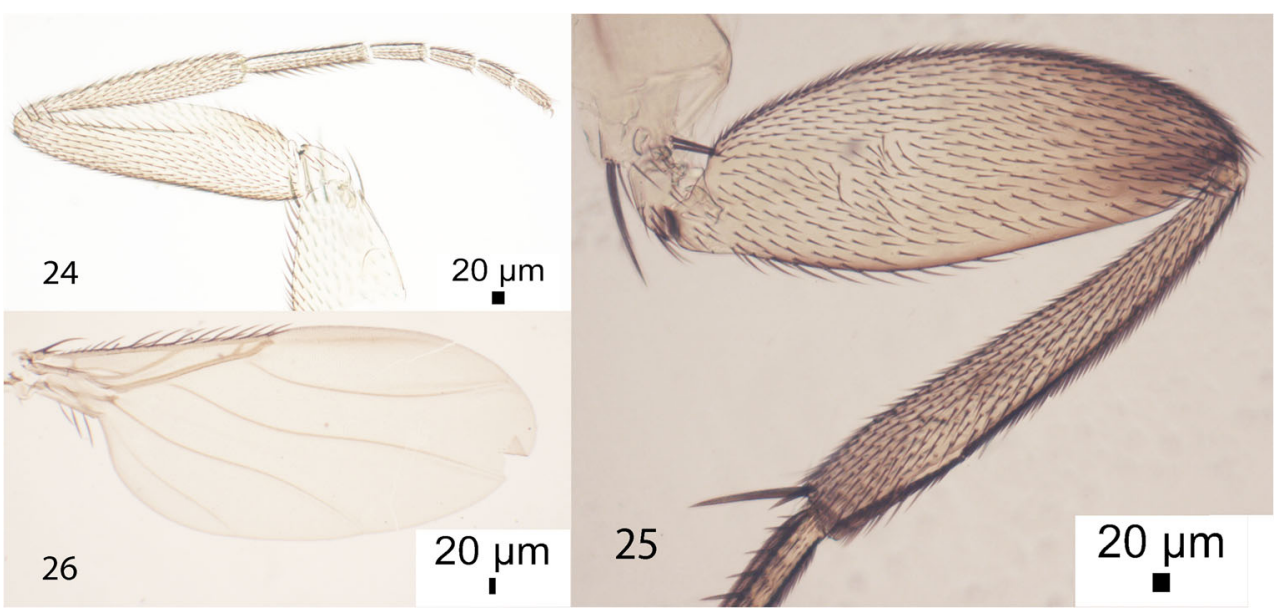

apical combs simple. Wing (Fig. 26) 1.45-1.83 mm long. Costal index 0.45-0.48. Costal ratios 2.92-3.47: 1.76-2.20: 1. Costal cilia (of section 3) $0.10-0.15 \mathrm{~mm}$ long. Vein 3 hair 0.02-0.03 mm long. 2-5 axillary bristles, the outermost being 0.10-0.12 mm long. Sc reaching R1. Haltere pale (Fig. 20).

Type material Holotype male, IRAN, East Azerbaijan, Chichecli Region, 38³9.899' N, 46³1.248' E, 2140 m a.s.1., 14.VI.2016, Samad Khaghaninia (35, UCMZ -13-104). Paratypes: 2 males, locality data as for the holotype (1 UCZM, 1 ICHMM).

Etymology Named after the need to beware (caveo) of its close resemblance to $M$. nectergata.

\section{Megaselia distincta Namaki-Khameneh \& Disney sp. n. (Figs. 27-38)}

Diagnosis (male) In the key to the males of British species (Disney 1989) it runs to couplet 139, where the hypopygium clearly differs from both options. Ten species from elsewhere or subsequently added run to the same couplet, but all have clearly different hypopygia. In addition, most are eliminated by having brown halteres and/or a costal index exceeding 0.4 and/or more than 2 axillary bristles and/or bristles as well as hairs on the epandrium. Megaselia hejazii (Namaki-Khameneh et al., 2019) most closely resembles the new species, but its hypopygium is clearly different. In the key to Palaearctic, Abteilung V (Schmitz and Delage 1974) it runs to couplet 5, but neither option applies.
Figs. 27-30 Megaselia distincta sp. n., male. 27 Whole fly; 28 frons; 29 detail of frons; $\mathbf{3 0}$ antennae, palps and proboscis
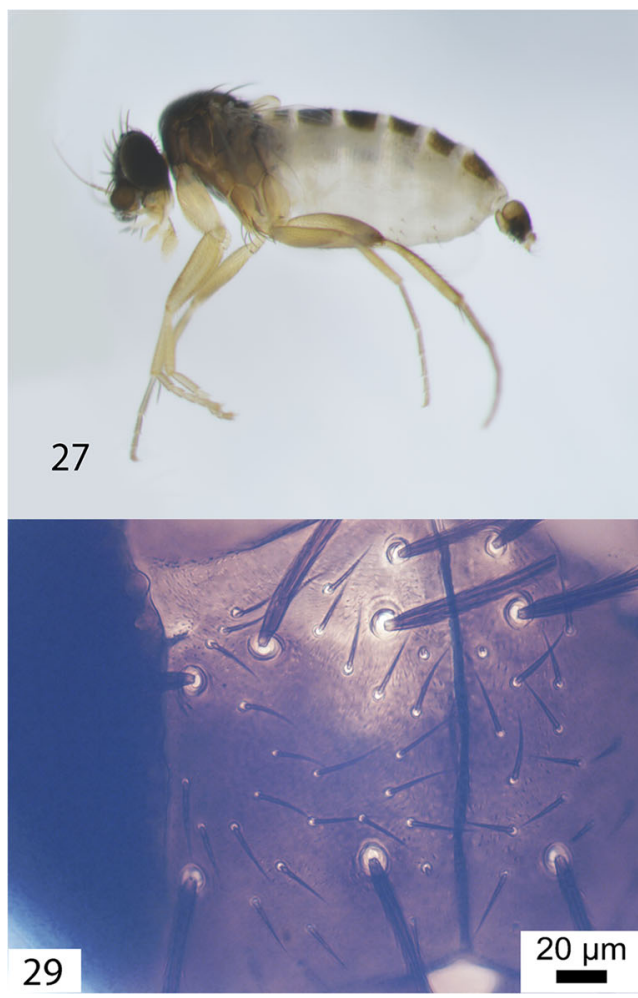

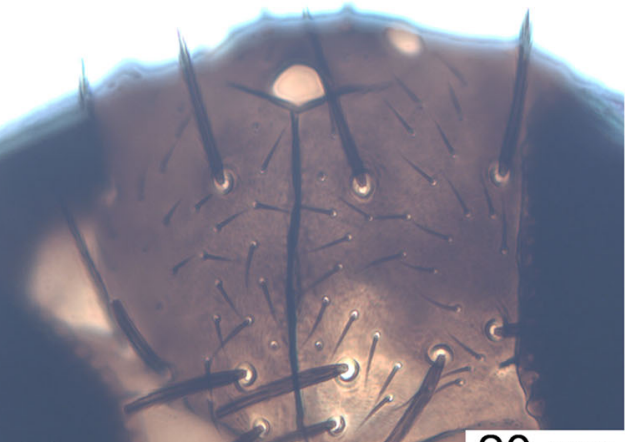

28

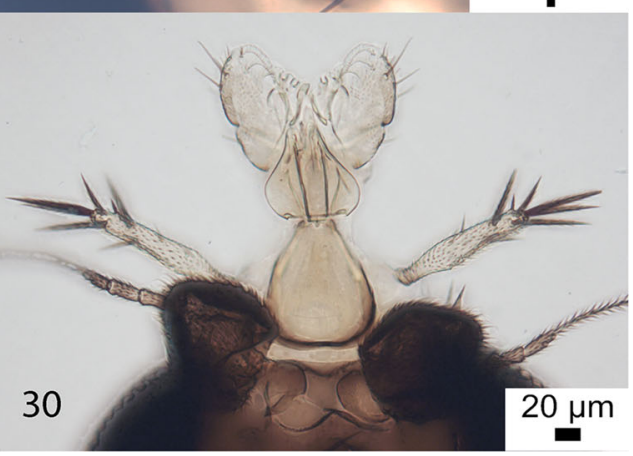


Figs. 31-38 Megaselia distincta sp. n., male. 31 Mesopleuron and notopleuron; 32 abdomen; 33 left face of hypopygium; 34 left face of epandrium; $\mathbf{3 5}$ right face of hypopygium; $\mathbf{3 6}$ front tarsus; $\mathbf{3 7}$ hind femur; 38 wing



Likewise for the rest of the world fauna the distinctive hypopygium, apart from other details, excludes this species.

Description (male) Whole fly as in Fig. 27. Frons as in Fig. 28, with dense but very fine microtrichia confined to the edges (Fig. 29). Postpedicels, which lack SPS vesicles, palps and proboscis as in Fig. 30, with the labella with lacking short spinules below. Thorax brown. Three notopleural bristles with no cleft in front of these and mesopleuron as in Fig. 31. Scutellum with an anterior pair of hairs and a posterior pair of bristles (Fig. 32). Abdominal tergites and venter as in Fig. 33, the latter with hairs on segments 3-6. Hypopygium as in Figs. 34 and 335. Legs yellowish brown to yellow. Fore tarsus with posterodorsal hair palisade on segments $1-4$ and 5 clearly longer than 4 (Fig. 36) and basitarsus with one row of small spinules. Dorsal hair palisade of mid tibia extends only about 0.35 times its length. Hairs below basal half of hind femur as in Fig. 37. Hind tibia with a dozen moderately differentiated posterodorsal hairs, without anterodorsals, and spinules of apical combs simple. Wings
(Fig. 38) 1.0-1.1 mm long. Costal index 0.36. Costal ratios 4.12: 0.47: 1. Costal cilia (of section 3) $0.09 \mathrm{~mm}$ long. Vein 3 hair $0.03 \mathrm{~mm}$ long. 2 unequal axillary bristles, the outermost being $0.09 \mathrm{~mm}$ long. Sc not reaching R1. Haltere knob pale yellowish.

Type material Holotype male, IRAN, West Azerbaijan, Mahabad City, $36^{\circ} 34.16^{\prime} \mathrm{N}, 45^{\circ} 41.21^{\prime} \mathrm{E}, 1521 \mathrm{~m}$ a.s.l., 18.VI.2018. Samad Khaghaninia (87, UCMZ, 13-102). Paratypes: 2 males, locality data as the holotype (ICHMM).

Etymology Named after its distinctive hypopygium.

\section{Megaselia fereagarici Namaki-Khameneh \& Disney sp. n. (Figs. 39-50)}

Diagnosis (male) In the key to the males of the British species (Disney 1989) this runs to couplet 244, but is immediately distinguished from both options by its hypopygium. In 
Figs. 39-46 Megaselia fereagarici sp. n., male. 39 Whole fly; $\mathbf{4 0}$ frons; $\mathbf{4 1}$ antennae palps and proboscis; $\mathbf{4 2}$ postpecicel; $\mathbf{4 3}$ side of thorax; $\mathbf{4 4}$ abdomen; $\mathbf{4 5}$ left face of hypopygium; 46 left face of epandrium

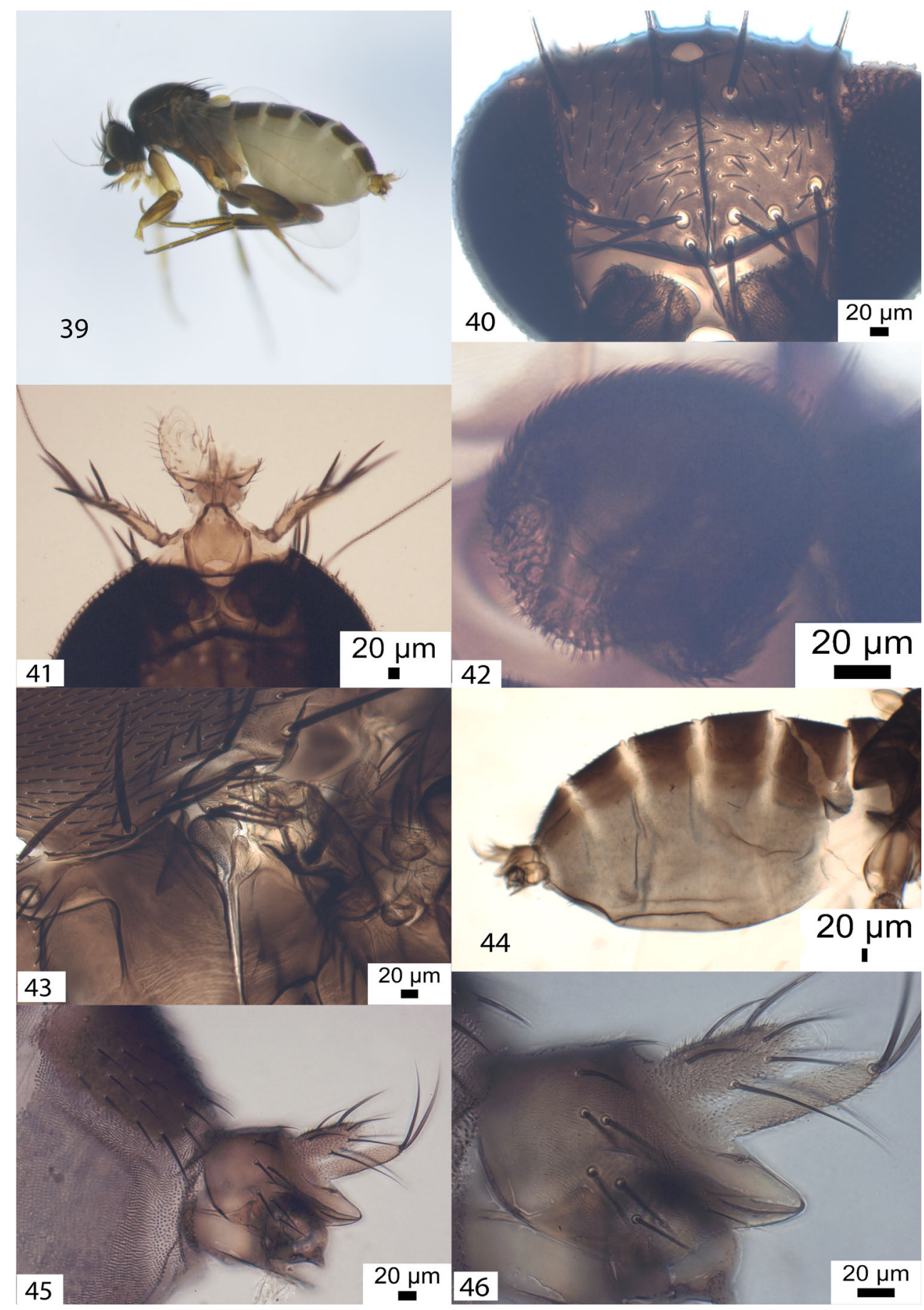

Borgmeier's (1966) key to Nearctic species it runs to Group VII couplet 10 lead 1 to the European and Asian species M. bovista (Gimmerthal, 1848). However, this was subsequently recognized as a misidentification of $M$. agarici (Lintner, 1895) prior to the description of the male of M. abdita Schmitz, 1959 (under its discarded synonym M. griseipennis Santos Abreu, 1921) (Disney 1987; ICZN 2012). Furthermore, Disney (2008) showed that the Nearctic M. agarici and Arabian and Oriental M. sandhui Disney, 1981 had also been confused. Our species closely resembles M. agarici but differs in the different left posterolateral lobe of the epandrium, more strongly differentiated bristles at the tip of the proctiger and the more abundant hairs on the abdominal venter.

Description (male) Whole fly as in Fig. 39. Frons as in Fig. 40, with dense but very fine microtrichia. Antennae, palps and proboscis as in Fig. 41, the postpedicels with a few obscure SPS 
Figs. 47-50 Megaselia fereagarici $\mathrm{n}$. sp., male. 47 Right face of hypopygium; $\mathbf{4 8}$ front tarsus; 49 hind femur, tibia and basitarsus; $\mathbf{5 0}$ wing

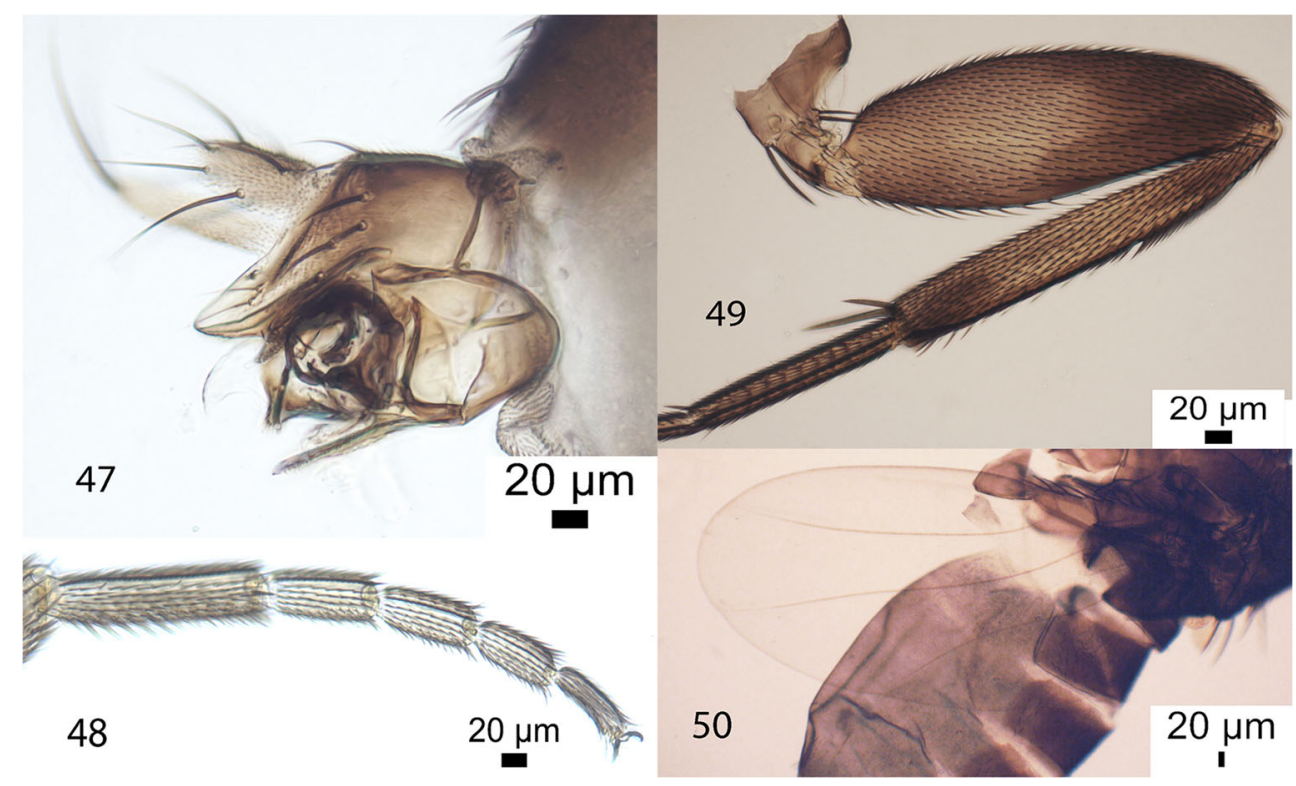

vesicles (Fig. 42). Thorax brown. With 3 notopleural bristles and no cleft in front of these and mesopleuron bare (Fig. 43). Scutellum with an anterior pair of small hairs and a posterior pair of bristles. Abdominal tergites and venter as in Fig. 44, the latter with only a few hairs on segments 3-6. Hypopygium as in Figs. 45, 46 and 47. Legs brown to yellowish brown, the front tibia and tarsus being pale yellow. Fore tarsus (Fig. 48) with posterodorsal hair palisades on segments $1-4$ and 5 a little longer than 4. Dorsal hair palisade of mid tibia extends about 0.63 times its length. Hairs below basal half of hind femur longer than those of anteroventral row of outer half (Fig. 49). Hind tibia with 1215 moderately differentiated posterodorsal hairs, without anterodorsals, and spinules of apical combs simple. Wings (Fig. 50) $1.75 \mathrm{~mm}$ long. Costal index 0.35. Costal ratios 3.99: 1.11: 1. Costal cilia (of section 3 ) $0.08 \mathrm{~mm}$ long. With 3 axillary bristles, the outermost being $0.14 \mathrm{~mm}$ long. Sc not reaching R1. Haltere knob pale yellow.

Type material Holotype male, IRAN, West Azerbaijan, Mahabad City, 36³4.16' N, 4541.21' E, $1521 \mathrm{~m}$ a.s.l., 9.VII.2018. Samad Khaghaninia (88, UCMZ, 13-102). Paratypes: 3 males, locality data as the holotype (ICHMM).

Etymology Named after it being near (fere) to $M$. agarici.

\section{Megaselia flavucrurus Namaki-Khameneh \& Disney sp. n. (Figs. 51-62)}

Diagnosis (male) In the key to the males of the British species (Disney 1989) this runs to couplet 292. However, this couplet
Figs. 51-53 Megaselia

flavucrurus sp. n., male. $\mathbf{5 1}$ whole fly; $\mathbf{5 2}$ frons; $\mathbf{5 3}$ antennae palps and proboscis

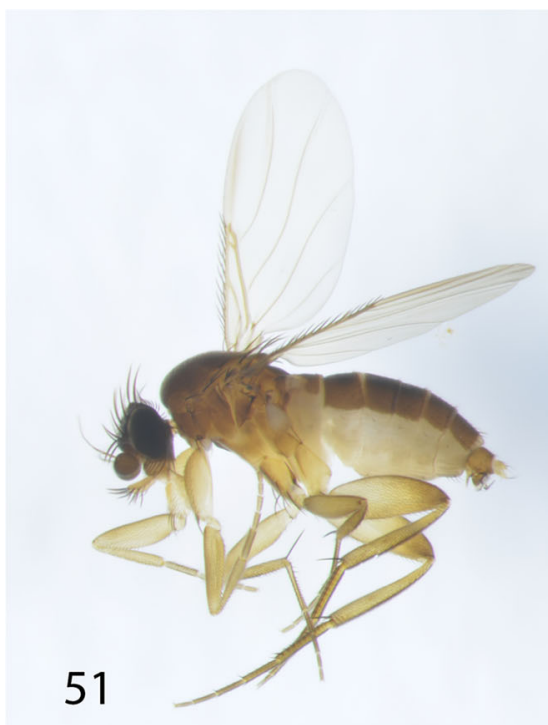

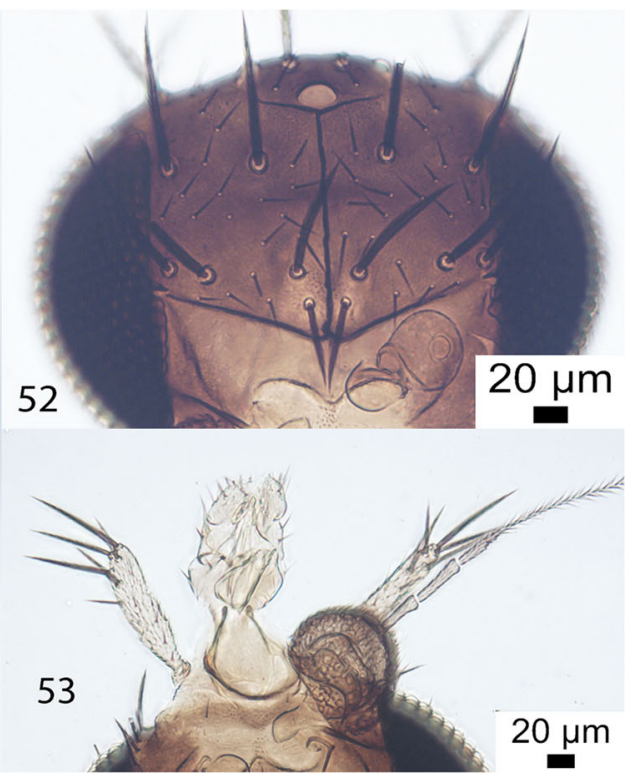


Figs. 54-62 Megaselia flavucrurus sp. n., male. 54 Postpedicel; 55 side of thorax; 56 abdomen; $\mathbf{5 7}$ left face of hypopygium; $\mathbf{5 8}$ left hypandrial lobe and penis complex; 59 right face of hypopygium; $\mathbf{6 0}$ front tarsus; $\mathbf{6 1}$ hind femur; $\mathbf{6 2}$ wing and haltere

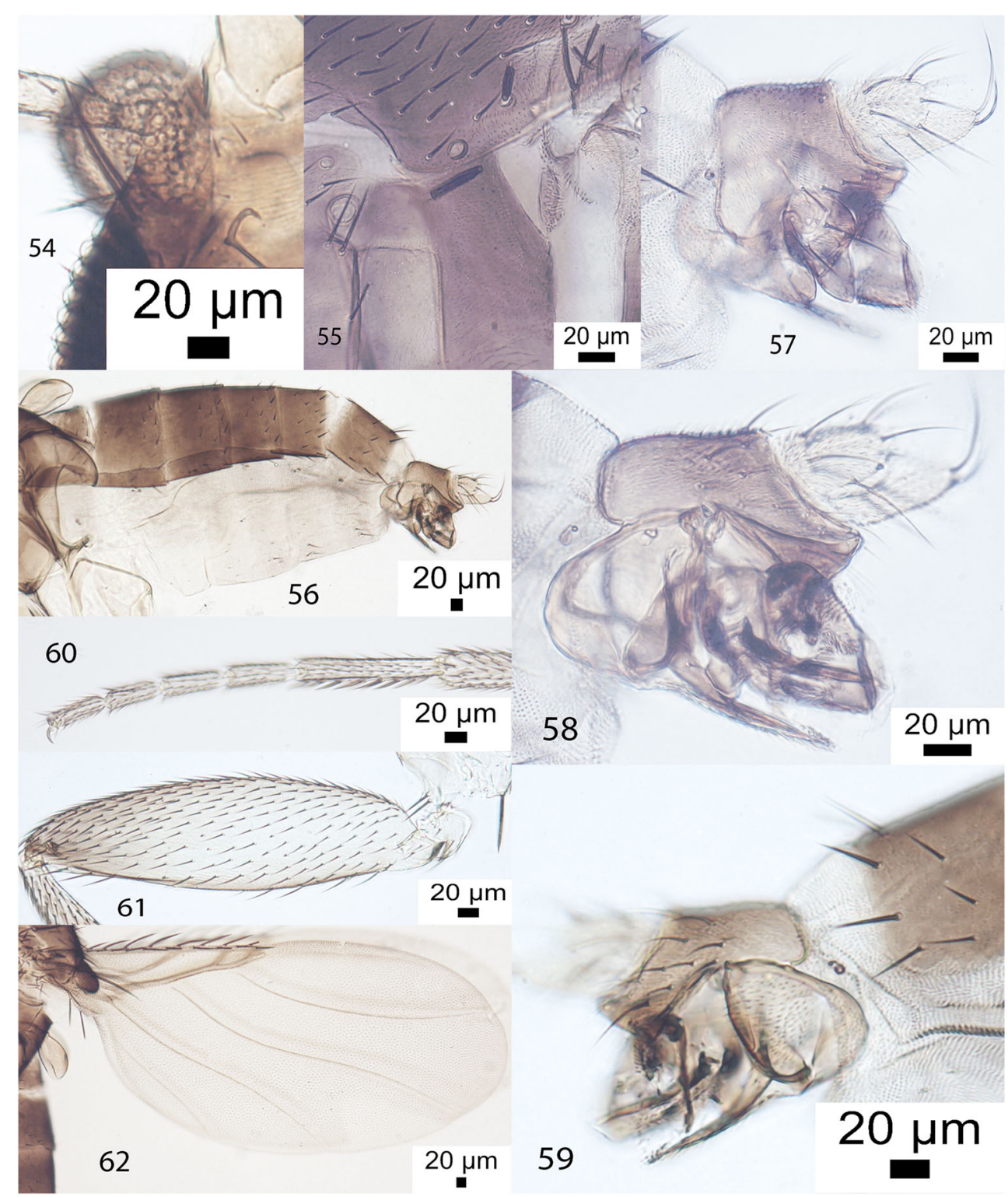

and those following have been replaced by a revision of the M. angusta (Wood, 1909) complex (Disney 1999). While it runs to couplet 19 , it is immediately distinguished from the rest of this complex by the combination of yellow legs, the costal index being 0.46 and the wing length being less than $1.5 \mathrm{~mm}$. This also excludes members of this complex from the rest of the world.

Description (male) Whole fly as in Fig. 51. Frons as in Fig. 52, with microtrichia restricted to the margins. Cheek with 2 bristles and jowl with 2 that are longer and more robust. Postpedicels, with SPS vesicles (Fig. 54), palps and proboscis as in Fig. 53. Thorax with 2 notopleural bristles and no cleft in front of these and mesopleuron bare (Fig. 55). Scutellum with an anterior pair of small hairs and a posterior pair of long bristles. Abdomen as in Fig. 56, the venter with fine hairs on segments 3-6. Hypopygium as in Figs. 57-59. Legs yellow. Front tarsus as in Fig. 60, with a posterodorsal hair palisade in segments 1-4. Dorsal hair palisade of mid tibia extends about 0.53 times its length. Hairs below basal half of hind femur shorter than those of anteroventral row of outer half (Fig. 61). Hind tibia with at least a dozen very finely differentiated posterodorsal hairs, without anterodorsals, and spinules of apical combs simple. Wings (Fig. 62) $0.85-0.89 \mathrm{~mm}$ long. Costal index 0.46. Costal ratios 3.2-3.5: 1.7-1.8: 1. Costal cilia (of section 3) $0.06 \mathrm{~mm}$ long. No hair at base of vein 3 . With 2 axillary bristles, the outermost being $0.06 \mathrm{~mm}$ long. Sc reaching R1. Haltere pale (Fig. 62).

Type material Holotype male, IRAN, West Azerbaijan, Mahabad City, 36²34.16' N, 4541.21' E, 1521 m a.s.l., 8.VII.2018. Samad Khaghaninia (89, UCMZ, 13-103). Paratypes: 5 males, locality data as the holotype (1 UCZM, 4 ICHMM). 
Figs. 63-70 Megaselia paluventer sp. n., male. 63 Whole fly; 64 frons; 65 antennae, palps and proboscis; 66 proboscis from below; 67 side of thorax; 68 abdomen; 69 left face of hypopygium; $\mathbf{7 0}$ right face of hypopygium

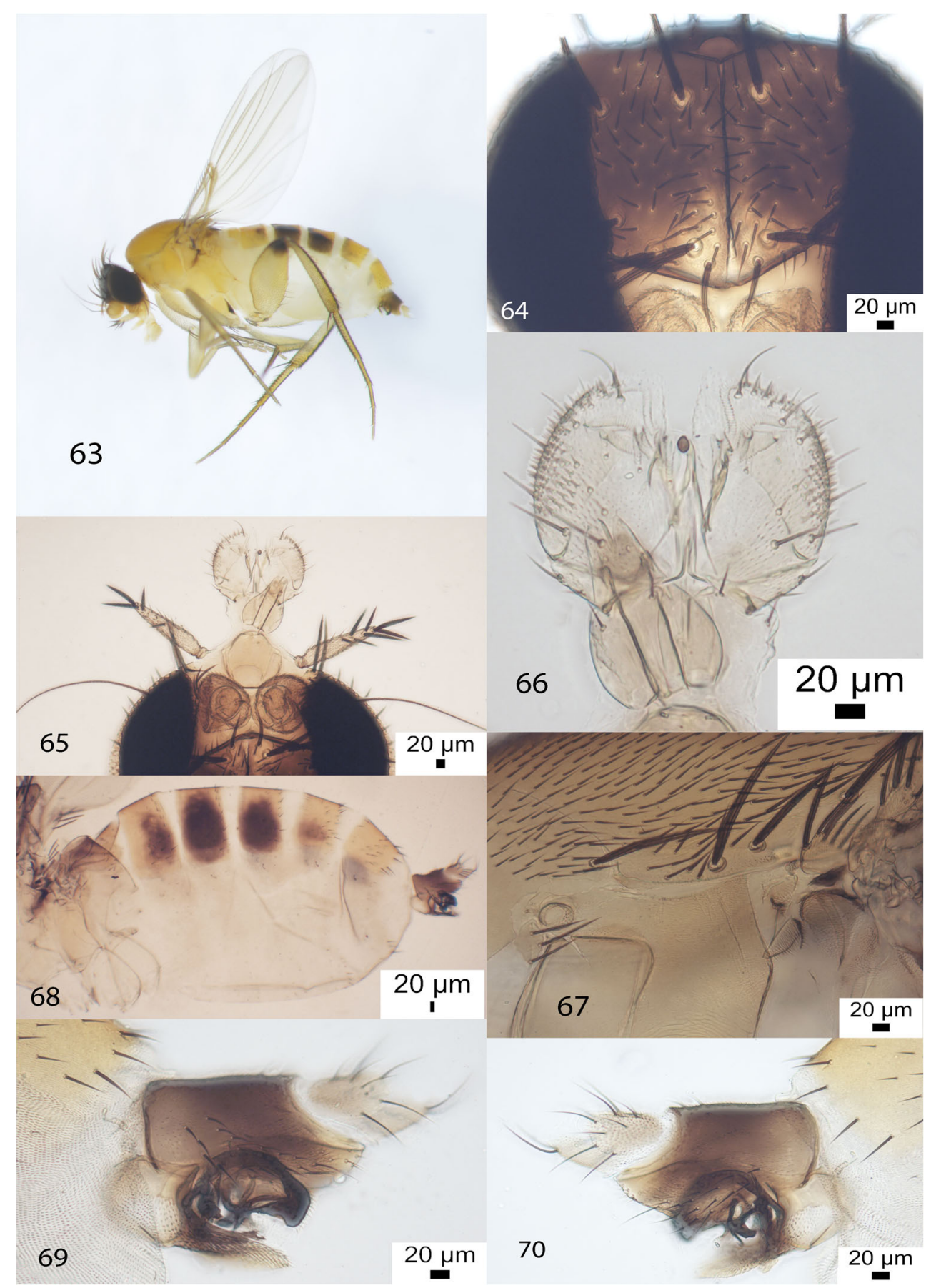

Etymology Named after its all yellow legs (flavus crurus).

\section{Megaselia paluventer Namaki-Khameneh \& Disney sp. n. (Figs. 63-74)}

Diagnosis (male) In the key to the males of the British species (Disney 1989) it runs to couplet 219, via couplet 218, to M. berndseni (Schmitz, 1919), but this species has the thorax, abdominal tergites and legs all brown. An additional four species will run to the same couplet, but apart from the colour of the tergites their hypopygia differ. Thus the epandrium of M. fomitopsis Naumov, 1992 has the height of its epandrium greater than its length and M. callunae Garcia-Romera \& Barrientos, 2014 has the hypandrial lobes subequal in length.

Description (male) Whole fly as in Fig. 63. Frons as in Fig. 64, with dense but very fine microtrichia over all but a fifth of its area. Cheek with 4 bristles and jowl with 2 that are much longer and more robust. Postpedicels, without SPS 
Figs. 71-74 Megaselia paluventer sp. n., male. 71 Right face of hypandrium; $\mathbf{7 2}$ front tarsus; $\mathbf{7 3}$ hind femur; $\mathbf{7 4}$ wing

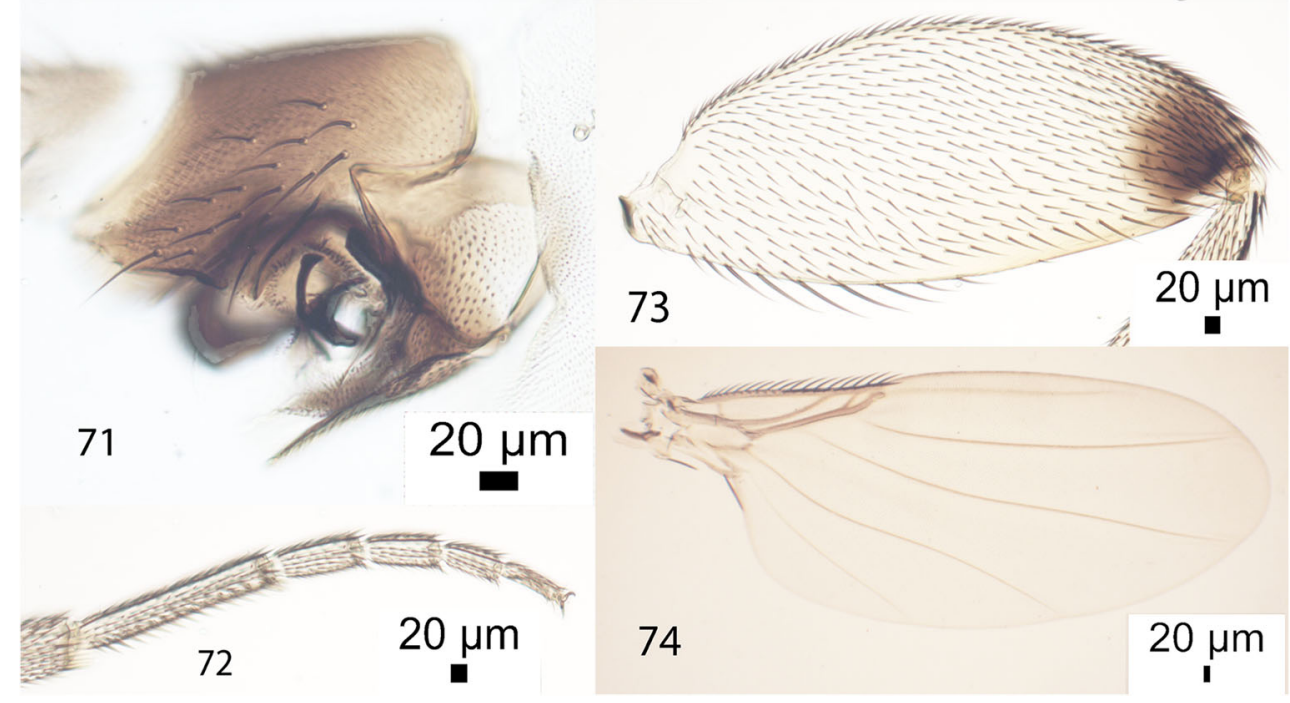

vesicles, palps and proboscis as in Fig. 65. Labella of proboscis with numerous short spinules below (Fig. 66). Side of thorax as in Fig. 67, with 2 notopleural bristles and no cleft in front of these and a bare mesopleuron. Scutellum with an anterior pair of small hairs and a posterior pair of bristles. Abdominal tergites and venter as in Fig. 68, and with only a few small hairs on segments 3-6 of the venter (Fig. 68). Hypopygium as in Figs. 69, 70 and 71. Legs yellow apart from the brown tips to the hind femora. Fore tarsus with posterodorsal hair palisade on segments $1-4$ and 5 longer than 4 (Fig. 72). Dorsal hair palisade of mid tibia extends about 0.77 times its length. Hairs below basal half of hind femur longer than those of anteroventral row of outer half (Fig. 73). Hind tibia with 10 differentiated posterodorsal hairs, without anterodorsals, and spinules of apical combs simple. Wings (Fig. 74) $1.7-1.8 \mathrm{~mm}$ long. Costal index 0.35-0.40. Costal ratios 1.3-1.4: 1.2-1.3: 1. Costal cilia (of section 3)
$0.05 \mathrm{~mm}$ long. Vein 3 hair $0.02 \mathrm{~mm}$ long. With 2 unequal axillary bristles, the outermost being $0.0 .06 \mathrm{~mm}$ long. Sc not reaching R1. Haltere yellow.

Type material Holotype male, IRAN, East Azerbaijan, Sharafkhaneh City, $38^{\circ} 11.05^{\prime} \mathrm{N}, 45^{\circ} 29.52^{\prime}$ E, 1313 m a.s.l., 21.VI.2018. Roya Namaki-Khameneh (73, UCMZ, 13-104). Paratypes: 40 males, locality data as the holotype (3 UCZM, 37 ICHMM).

Etymology Named after the pale (palus) abdominal venter.

\section{Megaselia polysetosis Namaki-Khameneh \& Disney sp. n. (Figs. 75-85)}

Diagnosis (male) In the key to the males of the British species (Disney 1989) it runs to couplet 126, but its hypoygium differs
Figs. 75-77 Megaselia polysetosis $\mathrm{sp}$. n., male. $\mathbf{7 5}$ Whole fly; 76 frons; 77 antennae, palps and proboscis




Figs. 78-85 Megaselia polysetosis sp. n., male. $\mathbf{7 8}$ Side of thorax; $\mathbf{7 9}$ abdomen; 80 left face of hypopygium; 81 left face of epandrium, hypandrium and penis complex; 82 right face of hypopygium; 83 front tarsus; 84 hind femur; 85 wings

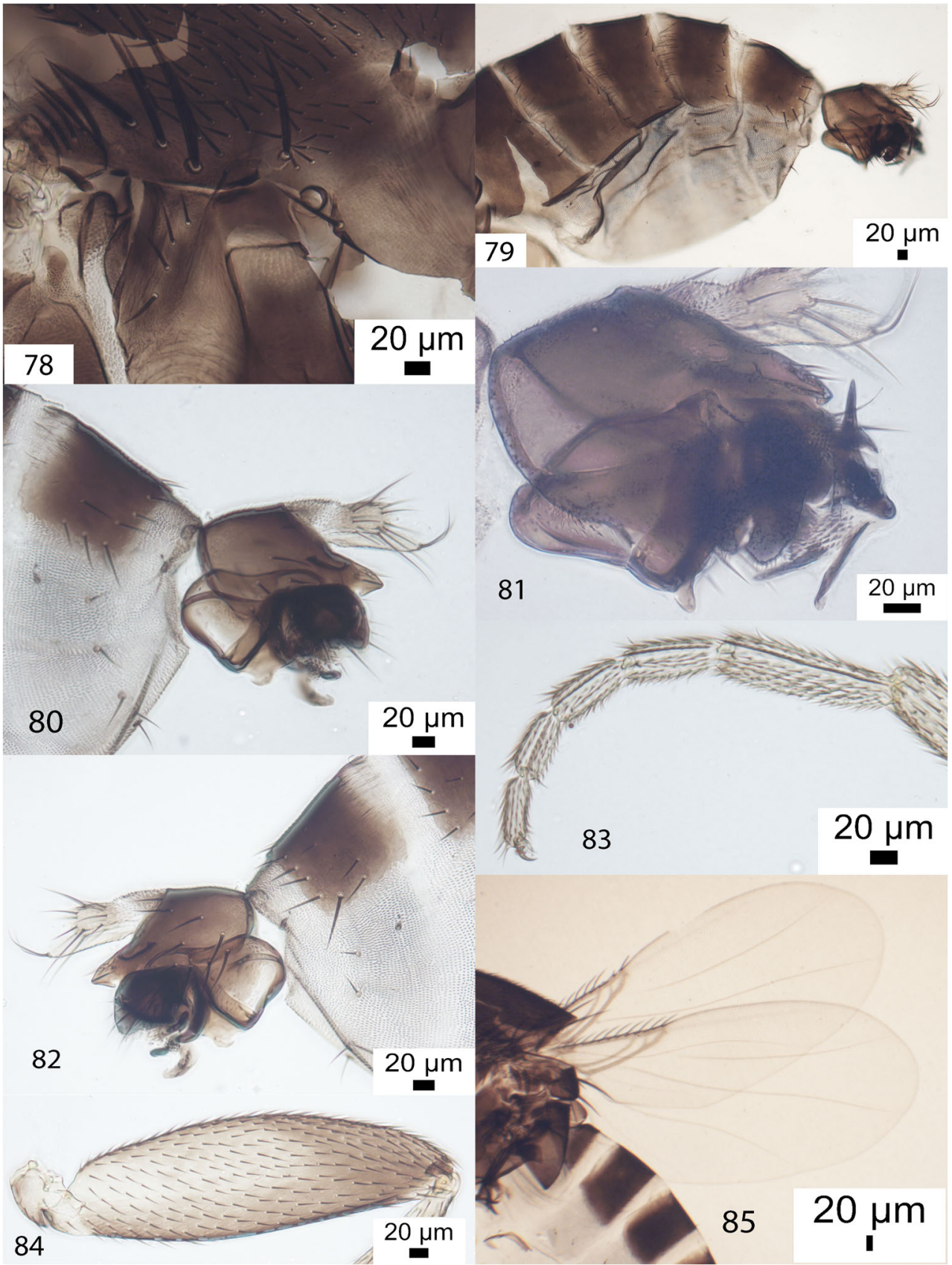

from both options. A dozen additions run to the same couplet, but most have a costal index exceeding 0.44 or if less the hypopygia clearly differ and some have brown palps and/or 4 axillary bristles. In the key of Schmitz and Delage (1974) to the Palaearctic, Abteilung V it runs to couplet 6 lead 1 to the Nearctic $M$. divergens (Malloch, 1912) instead of the Palaearctic M. fenestralis (Schmitz, 1919), which was subsequently rescued from synonymy with Malloch's species (Disney 1987). However, both species only have small hairs on the epandrium. Our species fails to fit any other species in the rest of the world fauna.
Description (male) Whole fly as in Fig. 75. Frons as in Fig. 76, with dense but very fine microtrichia. Cheek with 2 bristles and jowl with 2 that are longer and more robust. Antennae, whose postpedicelscis lack SPS vesicles, palps and proboscis as in Fig. 77. Thorax brown, with 3 notopleural bristles and no cleft in front of these and mesopleuron, which has only 3-6 hairs, as in Fig. 78. Scutellum with an anterior pair of small hairs and a posterior pair of bristles. Abdomen as in Fig. 79, the venter with a few small hairs on segments 4-6. Hypopygium as in Figs. 80, 81 and 82. Legs light brown to yellowish brown. Fore tarsus (Fig. 83) with posterodorsal hair 
Figs. 86-94 Phalacrotophora flavidus sp. n., male. 86 Whole fly; 87 head; 88 antenna; 89 side of thorax; 90 abdomen; 91 left face of hypopygium; 92 right face of hypopygium; 93 front tarsus; 94 hind legs

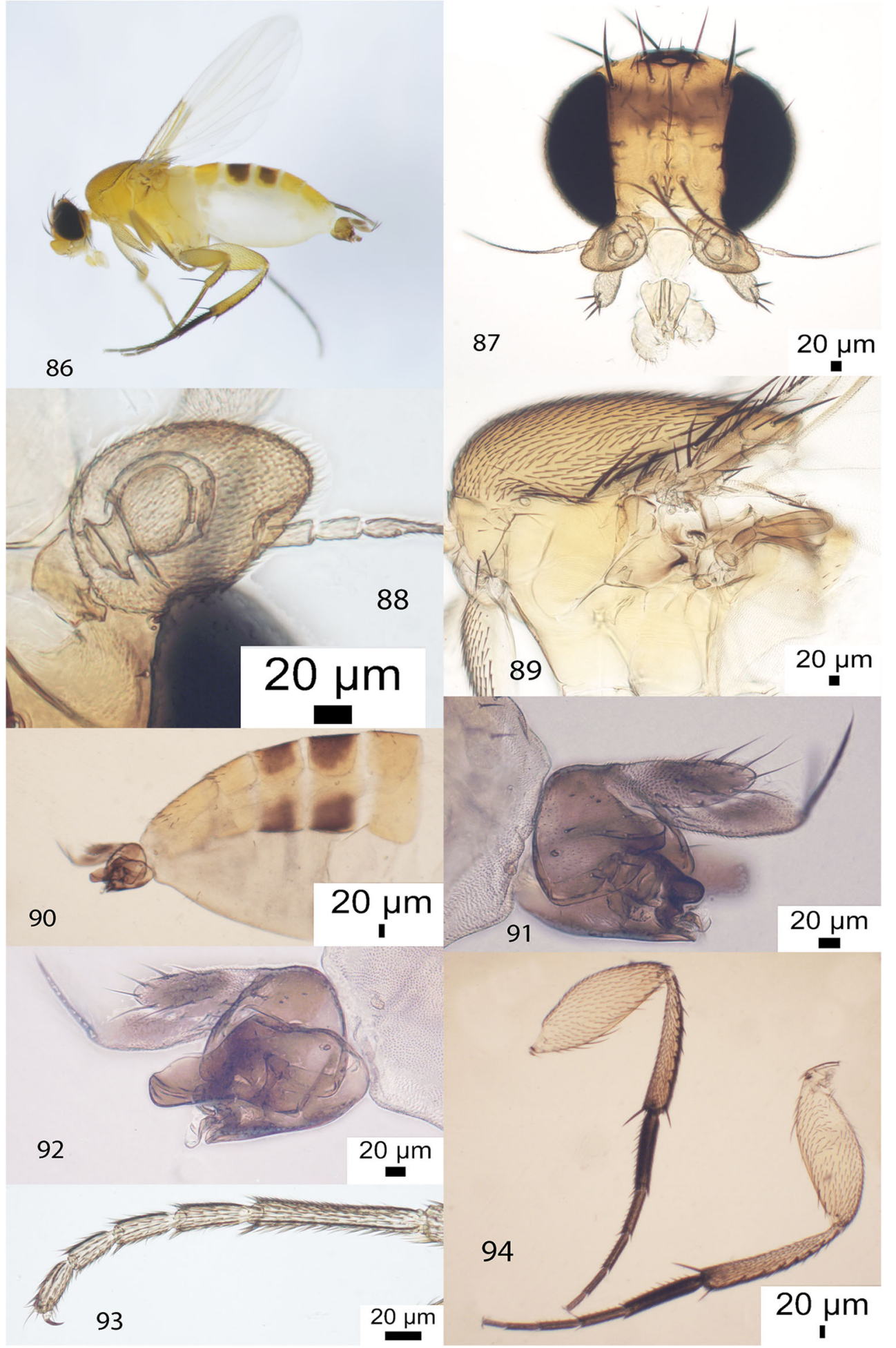

palisade on segments $1-4$ and 5 longer than 4. Dorsal hair palisade of mid tibia extends about 0.54 times its length. Hairs below basal half of hind femur not longer than those of anteroventral row of outer half (Fig. 84). Hind tibia with about a dozen moderately differentiated posterodorsal hairs, without anterodorsals, and spinules of apical combs simple.
Wings (Fig. 85) 1.08-1.11 mm long. Costal index 0.33-0.36. Costal ratios 3.9-4.8: 0.6-0.9: 1. Costal cilia (of section 3) $0.07 \mathrm{~mm}$ long. No hair on vein 3 . With 2 axillary bristles, the outermost being $0.10 \mathrm{~mm}$ long. Sc not reaching R1. Haltere brown. 
Figs. 95-100 Phora iranensis sp. n., male. 95 Whole fly; 96 frons; 97 palps and proboscis; 98 notopleuron; 99 abdomen; 100 left face of hypopygium

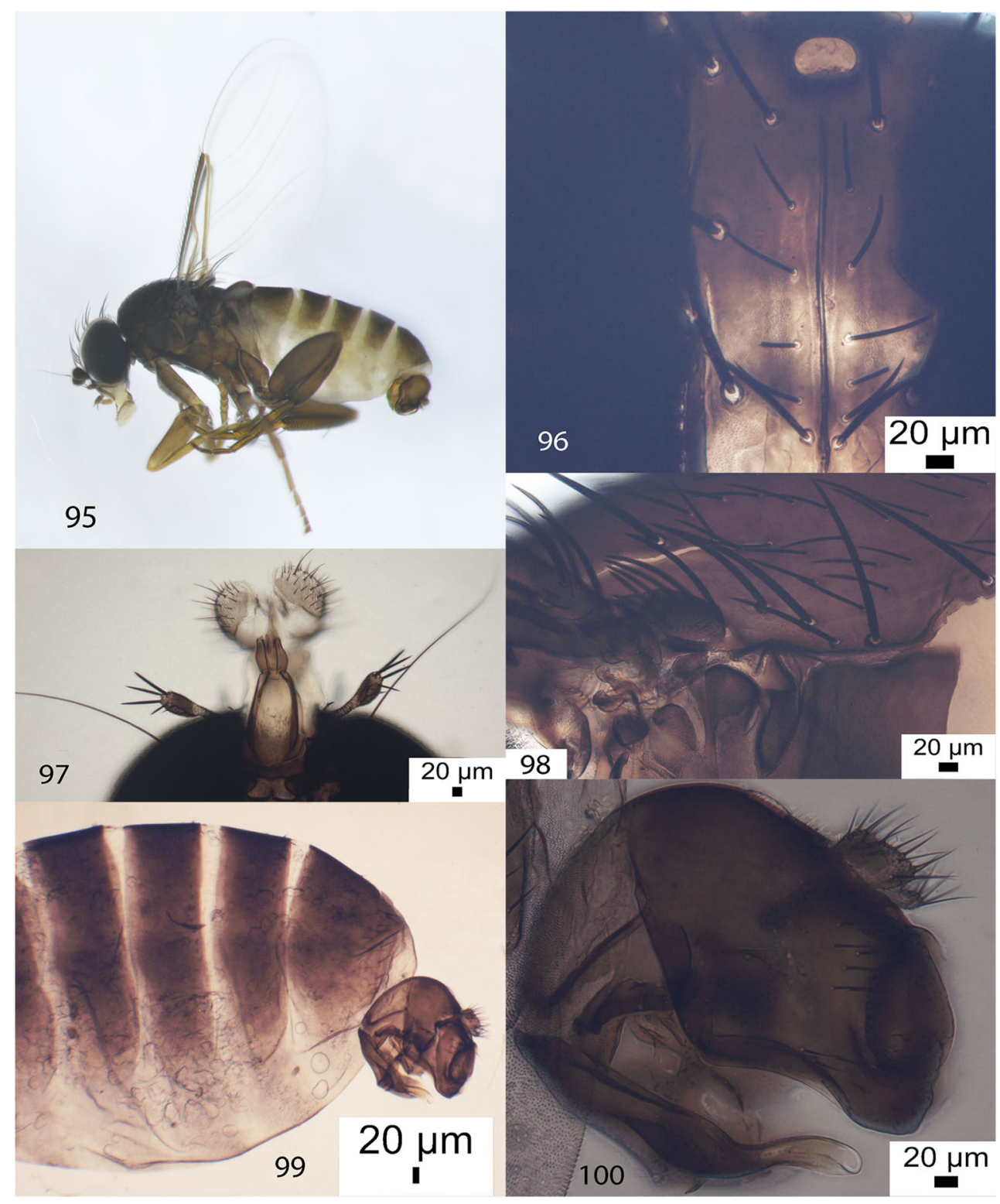

Type material Holotype male, IRAN, West Azerbaijan, Mahabad City, $36^{\circ} 34.16^{\prime} \mathrm{N}, 45^{\circ} 41.21^{\prime} \mathrm{E}, 1521 \mathrm{~m}$ a.s.1., 18.VI.2018. Samad Khaghaninia (85, UCMZ, 13-105). Paratypes: 45 males, locality data as the holotype (3 UCZM, 42 ICHMM).

Etymology Named after the many bristles on the epandrium (Greek many polys, plus Latin bristly setosis).

\section{Phalacrotophora flavidus Namaki-Khameneh \& Disney sp. n. (Figs. 86-94)}

Diagnosis (male) About fifty species are known in this cosmopolitan genus. European species are covered by Disney and Beuk (1997) supplemented by Durska et al. (2003), Lengyel (2009), Disney and Smith (2016). Many species can be excluded as they have a brown thorax. Three species have a brown hind basitarsus. These therefore resemble our species. However, the male $P$. fasciata (Fallén, 1823) has a wing about $2 \mathrm{~mm}$ long and the hypopygium is different. Another has a costal index of 0.46 and 4 nearly equal scutellar bristles. Finally the male of the Neotropical P. nedae (Malloch, 1912) has a wing length of about $1.8 \mathrm{~mm}$, a costal index of $0.40-0.41$ and a different hypopygium, with its yellow anal tube and very different right hypandrial lobe. Of the rest some have a pale hind basitarsus, apart from different hypopygia.

Description (male) Whole fly as in Fig. 86. Head as in Fig. 87, with breadth of frons being about 1.14 times the midline length. Antenna as in Fig. 88. The bristles of palps being $0.04 \mathrm{~mm}$ long. Side view of thorax as in Fig. 89, with the anterior scutellars measuring $0.06 \mathrm{~mm}$ in length and the 
Figs. 101-106 Phora iranensis sp. n., male. 101 Right face of hypopygium; 102 front leg; 103 mid femur and tibia; 104 hind leg; 105 base of hind femur; 106 wing and haltere

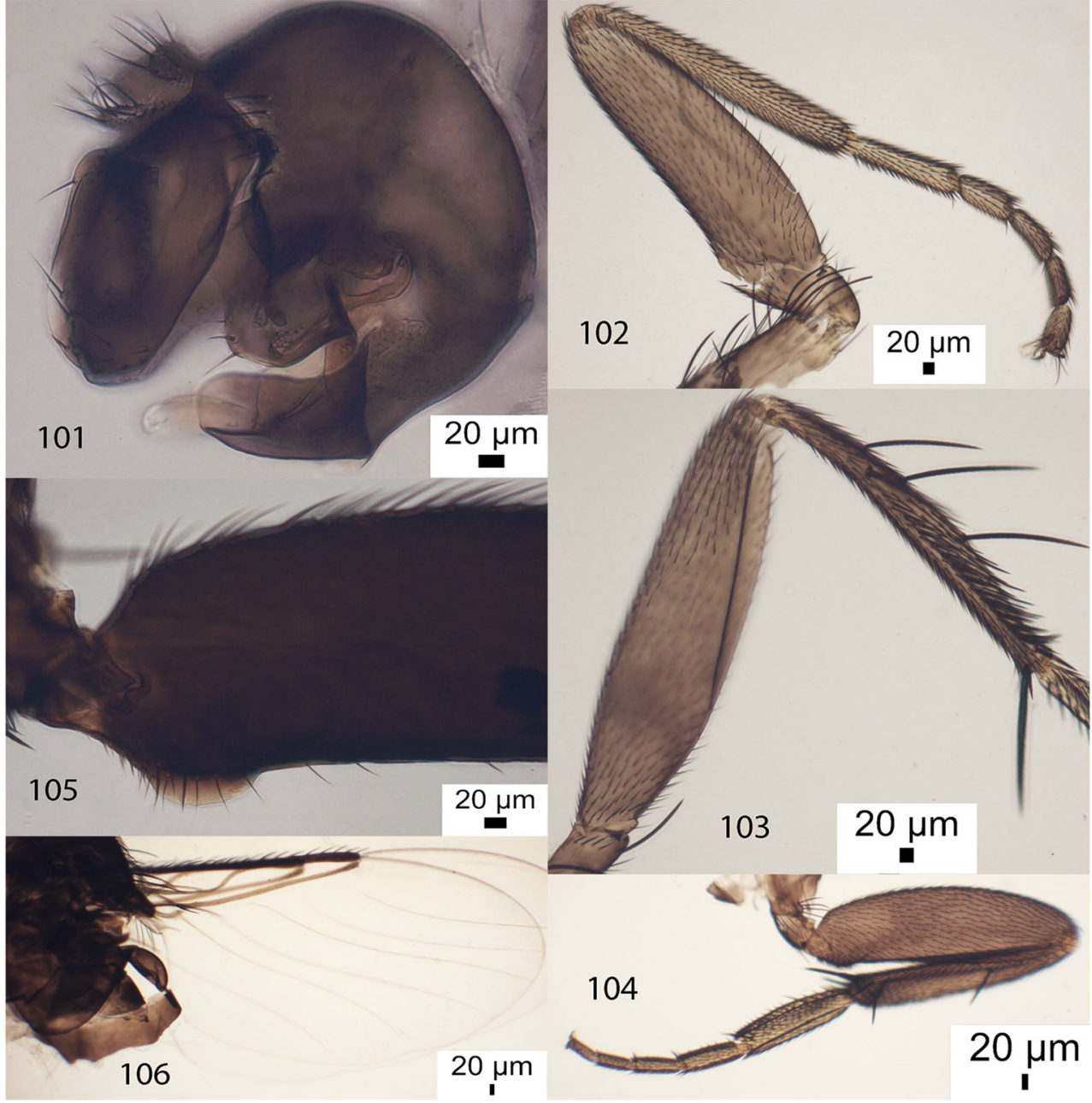

posterior pair $0.12 \mathrm{~mm}$. Abdomen as in Fig. 90. Hypopygium as in Figs. 91 and 92. Apart from the hind basitarsi the legs are yellow (Figs. 93 and 94). Wing $1.39 \mathrm{~mm}$ long. Costal index 0.36. Costal ratios 4.86: 1.51: 1 . With 2 unequal axillary bristles.

Type material Holotype male, IRAN, East Azerbaijan, Sharafkhaneh City, $38^{\circ} 11.05^{\prime} \mathrm{N}, 45^{\circ} 29.52^{\prime}$ E, $1313 \mathrm{~m}$ a.s.l., 27.VII.2018. Roya Namaki-Khameneh (70, UCMZ, 13-101).

Etymology Named after the dominantly yellow colour.

\section{Phora iranensis Namaki-Khameneh \& Disney sp. n. (Figs. 95-106)}

Diagnosis (male) Around 70 species of Phora Latreille, 1796 are known, with most being north temperate in distribution. The European species are covered by Disney (1983) supplemented by Schmitz $(1953,1955)$, Disney $(1989,1993)$ and Mostovski (2002a). The Asian species are covered by Schmitz (loc. cit.) supplemented by Gotô's (1986) key to Japanese species, additions by Zaitzev (1989), by Michailovskaya (1999, 2004a, b), who provides keys to the species of the Russian far east, Mostovski (2002a, b), Mostovski and Disney (2001). Gotoh (2006) added further Oriental and Eastern Palaearctic species, many of which are included in the key to Chinese species by Liu and Wang (2010). Most of the species can be eliminated by one or more of the following features; the frons not being narrowed dorsally, the right surstylus of the hypopygium not being bilobed, the left side of the epandrium not being deeply cleft and the antero-dorsal bristles of the basal halves of the tibia being none on the front tibia and only one on the mid and hind tibiae. Of the few remaining species for consideration their hypopygia all clearly differ.

Description (male) Whole fly as in Fig. 95. Frons as in Fig. 96. Antennae dark brown to black, the arista being devoid of microsetae. Palps and proboscis as in Fig. 97. Notopleuron as in Fig. 98, with 3 longer bristles and one that is shorter. Scutellum with an anterior pair of hairs (about as long as those on scutum) and a posterior pair of bristles. Mesopleuron bare. 
Abdomen as in Fig. 99. Hypopygium as in Figs. 100 and 101. Front leg as in Fig. 102. Mid femur and tibia as in Fig. 103. Hind leg as in Fig. 104, with the base of the hind femur as in Fig. 105. Wing (Fig. 106) $1.94 \mathrm{~mm}$ long. Costal index 0.45 . Costal section 1 about 1.64 times as long as section 2. With 4 axillary bristles ( $0.14 \mathrm{~mm}$ in length), Hair at base of vein 3 $0.11 \mathrm{~mm}$ long. Costal cilia $0.07 \mathrm{~mm}$ long. Haltere brown (Fig. 106).

Type material Holotype male, IRAN, West Azerbaijan, Mahabad City, $36^{\circ} 34.16^{\prime} \mathrm{N}, 45^{\circ} 41.21^{\prime}$ E, $1521 \mathrm{~m}$ a.s.l., 29.VII.2018. Samad Khaghaninia (68, UCMZ, 13-102). Paratypes: 3 males, locality data as the holotype (ICHMM).

Etymology Named after the country of the holotype.

\section{A key to the species described in this paper.}

It is necessary to refer to the figures, and those of the hypopygia in particular, to confirm the identifications.

Apex of third antennal segment drawn out into long (genus Iranphora) $\ldots 2$

- Apex of third antennal segment not drawn out in this way..................................... 3

Notopleuron with 3 bristles, mesopleuron bare, abdominal tergites with small hairs largely restricted to hind margins, venter pale and lacking hairs. Hypopygium pale with the pale anal tube that is longer than epandrium, Wings $0.87 \mathrm{~mm}$ long. Costal index 0.64, Haltere knob brown (Figs . 1, 4, 6, 7, 8, 14 and $15)$ Iranphora sharafkhaneensis

- Without this combination other species

Hind tibia simply haired on dorsal face, but may bear isolated bristles (genus Phora) ..............4

- Hind tibia with one or more dorsal or near dorsal longitudinal palisade-like rows of setae............5

Left side of the epandrium not being deeply cleft, hypopygium as in Fig. 100 ..... Phora iranensis

- Without this combination other species

Male with proctiger ending in finely-feathered bristles that are clearly more robust than setae on cerci, hind tibia with a clearly differentiated longitudinal row of stout, spine-like, antero-dorsal hair (genus

Phalacrotophora) 6

- Male with proctiger ending in setae that little, if any, stronger than those on cerci, hind tibia without a clearly differentiated row of spine-like anterodorsal hairs (genus Megaselia) . .7

Apart from the hind basitarsus the legs are yellow, Wing $1.39 \mathrm{~mm}$ long, costal index 0.36, Hypopygium as in Figs. 91 and 92 Phalacrotophora flavidus

- Without this combination other species

Mesopleuron with hairs 8

- Mesopleuron bare 9

Haltere with stem and knob largely dark, hypopygium as in Figs. 80-82 . Megaselia polysetosis

- Haltere with knob mainly yellow, hypopygium as in Figs. 33-35 Megaselia distincta

Notopleuron with three strong bristles, hypopygium as in Figs. 45-47 Megaselia fereagarici

- Notopleuron with only two strong bristles, hypopygium different 10

Vein Sc clearly ending before reaching R1, hypopygium as in Figs. 69-71. Megaselia paluventer

- Vein Sc reaches R1, hypopygium different 11

Hairs below basal half of hind femur longer than those of antero-ventral row of outer half, hypopygium as in Figs. 69-71 Megaselia caveonectergata

- Hairs below basal half of hind femur shorter than those of antero-ventral row of outer half, hypopygium as in Figs. 21-23 Megaselia flavucrurus

\section{Comments}

It is evident that the scuttle fly fauna of Iran is still poorly known. Furthermore for most of the new species described above and in our cited papers only males are known. 
Acknowledgments RHLD's studies of Phoridae are currently supported by a grant from the Balfour-Browne Trust Fund (University of Cambridge).

\section{Declarations}

Conflict of interest The authors declare they have no conflict of interests.

The authors did not receive support from any organization for the submitted work.

Open Access This article is licensed under a Creative Commons Attribution 4.0 International License, which permits use, sharing, adaptation, distribution and reproduction in any medium or format, as long as you give appropriate credit to the original author(s) and the source, provide a link to the Creative Commons licence, and indicate if changes were made. The images or other third party material in this article are included in the article's Creative Commons licence, unless indicated otherwise in a credit line to the material. If material is not included in the article's Creative Commons licence and your intended use is not permitted by statutory regulation or exceeds the permitted use, you will need to obtain permission directly from the copyright holder. To view a copy of this licence, visit http://creativecommons.org/licenses/by/4.0/.

\section{References}

Abdi-Goodarzi M, Moharrami M, Karimi G (2013) Identification of phorid fly Megaselia scalaris (Diptera: Phoridae) in Iranian honey bee (Apis mellifera meda) colonies of Taleghan, Karadj apiaries. Iran HoneyBee Sci Technol 3:9-13

Ament DC (2017) Phylogeny of Phorinae sensu latu (Diptera: Phoridae) inferred from a morphological analysis with comprehensive taxon sampling and an uncommon method of character coding. Zool J Linn Soc 181(1):151-188

Borgmeier T (1966) Revision of the north American Phorid flies. Part III. (the species of the genus Megaselia, subgenus Megaselia (Diptera, Phoridae)). Stud Entomol 7:257-416

Disney RHL (1983) Scuttle flies Diptera, Phoridae (except Megaselia). Handbooks for the Identification of British Insects 10, part 6. Royal Entomological Society, London

Disney RHL (1987) The undescribed male and holarctic status of Megaselia abdita Schmitz (Diptera: Phoridae). Entomol Scand 18: 263-264

Disney RHL (1989) Scuttle flies - Diptera Phoridae genus Megaselia. Handbooks for the Identification of British Insects 10, part 8 . Royal Entomological Society, London

Disney RHL (1993) Notes on European Phoridae (Diptera). British J Nat Hist 6:107-118

Disney RHL (1994) Scuttle flies: the Phoridae. Chapman \& Hall, London, U. K. https://doi.org/10.1007/978-94-011-1288-8 6

Disney RHL (1999) A troublesome sibling species complex of scuttle flies (Diptera: Phoridae) revisited. J Nat Hist 33:1159-1216. https://doi.org/10.1080/002229399299987

Disney RHL (2001) The preservation of small Diptera. Entomol Mag 137:155-159

Disney RHL (2008) The identification of Megaselia sandhui Disney and M. agarici (Lintner), scuttle fly pests (Diptera: Phoridae) of cultivated mushrooms (Agaricales: Agaricaceae). Entomol Gaz 59:243-249

Disney RHL, Beuk PLT (1997) European Phalacrotophora (Diptera: Phoridae). Entomol Gaz 48:185-192
Disney RHL, Smith DA (2016) A new species of Phalacrotophora Enderlein (Diptera: Phoridae) from England. Entomol Mag 152: 189-192

Disney RHL, Barzegar S, Zamani AA, Abbasi S, Vafaei Shoushtari R (2012) Two new species of Megaselia Rondani (Diptera, Phoridae) reared from fungi in Iran. Fragm Faun 55:41-48. https://doi.org/10. 3161/00159301FF2012.55.1.041

Durska E, Ceryngier P, Disney RHL (2003) Phalacrotophora beuki (Diptera: Phoridae), a parasitoid of ladybird pupae (Coleoptera: Coccinellidae). Eur J Entomol 100:627-630. https://doi.org/10. 14411/eje.2003.092

Ebrahimi S, Karimi J, Modarres Awal M, Fekrat L (2014) A newly recorded genus and species of Megaseliini (Diptera: Phoridae), a parasitoid of ladybird pupae (Coleoptera: Coccinellidae), from Iran. Entomofauna 35(19):425-432

Ghavami MB, Djalilvand A (2015) First record of urogenital Myiasis induced by Megaselia scalaris (Diptera: Phoridae) from Iran. J Arthropod Borne Dis 9(2):274-280

Gotô T (1986) Systematic study of the genus Phora Latreille from Japan (Diptera, Phoridae). Kontyû 54:128-142

Gotoh T (2006) The genus Phora (Diptera, Phoridae) from Nepal, Taiwan and neighbouring countries. Bull Kitakyushu Mus Natur Hist Hum Hist Ser A (Nat Hist) 4:9-38

ICZN (2012) Opinion 2292 (case 3521). Bull Zool Nomenclature 69:7274

Lengyel GD (2009) Phalacrotophora species (Diptera: Phoridae) with four subequal scutellar setae and notes on other Europeran species. Zootaxa 2172:59-68. https://doi.org/10.5281/zenodo.189239

Liu G, Wang B (2010) Two new species of Phora Latreille (Diptera: Phoridae) from China, with a key to species. Zootaxa 2359:35-42. https://doi.org/10.11646/zootaxa.2359.1.2

Michailovskaya MV (1999) A review of the genera Triphleba Rondani, Phora Latreille and Anevrina Lioy (Diptera, Phoridae) from Russian Far East. Far East Entomol 70:1-16

Michailovskaya MV (2004a) Scuttle flies (Diptera, Phoridae) of the Far East of Russia. Russian Academy of Sciences far eastern branch. Dalnauka, Vladivostok [In Russian]

Michailovskaya MV (2004b) 31. Diptera. 60. Fam. Phoridae in: key to the insects of Russian Far East. Vol. VI. Diptera and Siphonaptera. Pt 3. Vladivostok, Dalnauka, pp 9-40. [In Russian]

Mostovski MB (2002a) Three new species of Palaearctic Phora Latreille (Dipt., Phoridae) with notes on other species and new synonyms. Entomol Mag 138:23-28

Mostovski MB (2002b) Two new species of Phora (Dipt., Phoridae) from Tajikistan and India. Entomol Mag 138:237-240

Mostovski MB, Disney RHL (2001) A new species of Phora (Diptera: Phoridae) from Kamchatka, with comments on the groundplan of the family. Entomol Probl 32:79-83

Namaki-Khameneh R, Khaghaninia S, Disney RHL (2018) New records of the scuttle flies (Diptera, Phoridae) from Iran. J Insect Biodivers Syst 4(3):147-155

Namaki-Khameneh R, Khaghaninia S, Disney RHL (2019a) Scuttle flies (Diptera: Phoridae) from Ardabil province in Iran, with description of a new species of Megaselia Rondani. Zool Middle East 65(1):70 74. https://doi.org/10.1080/09397140.2018.1540155

Namaki-Khameneh R, Khaghaninia S, Disney RHL (2019b) Records of species of Megaselia Rondani 1856 (Diptera, Phoridae) from West Azerbaijan province including new records for Iran. J Crop Prot 8(2):235-242

Namaki-Khameneh R, Khaghaninia S, Disney RHL, Maleki-Ravasan N (2019c) Faunistic study of the genus Megaselia Rondani 1856 (Diptera: Phoridae) from East Azerbaijan province including 11 new records for Iran. J Appl Plant Prot 8(1):45-56 [in Persian]

Namaki-Khameneh R, Khaghaninia S, Disney RHL, Maleki-Ravasan N (2019d) Twenty one new species of Megaselia Rondani (Diptera: 
Phoridae) from Iran. Zootaxa 4711(1):001-050. https://oi.org/10. 11646/zootaxa.4711.1.1

Rabieh MM, Prescher S, Alikhani M, Arkani T (2013) Review of scuttle flies (Diptera: Phoridae) from Iran, with first records for Iran and Asia. Studia Dipt 20(1):23-30

Sadeghi S, Weber G, Fallahzadeh M, Dousti AF (2013) Introduction to the scuttle flies Fauna (Diptera: Phoridae) of Fars Province, Iran. Linzer Biol Beitr 45(2):2019-2024

Schmitz H (1953) Phoridae. In: Lindner E (ed) Die Fliegen der palaearktischen Region 4(33), Lieferung 171:273-320 (1952). Schweizerbart'sche Verlagsbuchhandlung, Stuttgart

Schmitz H (1955) Phoridae. In: Lindner E (ed) Die Fliegen der palaearktischen Region 4(33), Lieferung 180:321-368. Schweizerbart'sche Verlagsbuchhandlung, Stuttgart

Schmitz H, Delage A (1974) Phoridae. In: Lindner E (ed) Die Fliegen derpalaearktischen Region 4(33), Lieferung 301:638-664. Schweizerbart'sche Verlagsbuchhandlung, Stuttgart

Solgi R, Dinparast Djadid N, Eslamifar A, Raz A, Zakeri S (2017) Morphological and molecular characteristic of Megaselia scalaris
(Diptera: Phoridae) larvae as the cause of urinary myiasis. J Med Entomol 54(3):781-784. https://doi.org/10.1093/jme/tjw204

Talebi AA, Zamani AA, Mohammadi Goltapeh E (2003) Identification and description of some Diptera pest of white button mushroom, Agaricus bisporus. J Pests Plant Dis 71:91-102 [in Persian]

Zaitzev VF (1989) 47. Family Phoridae. In: Bei-Bienko, GYa, Steyskal, GC (eds) keys to the insects of the European part of the USSR. V. Diptera and Siphonaptera. Amerind Publishing Co., New Delhi, pp $1156-1233$

Zamani AA, Talebi AA, Mohammadi Goltapeh E, Fathipour Y (2005) Investigation on morphological and biological characteristics of Megaselia scalaris (Diptera: Phoridae), as an important pest of button mushroom in Karaj, Iran. Sci J Agric 27(2):45-58 [in Persian]

Publisher's note Springer Nature remains neutral with regard to jurisdictional claims in published maps and institutional affiliations. 